\title{
Prevalence and psychological impact of Acne vulgaris among female secondary school students in Arar city, Saudi Arabia, in 2018
}

\author{
Manal Saeed Alanazi ${ }^{1}$, Sabry Mohamed Hammad ${ }^{2}$, Amal Elwan Mohamed ${ }^{3}$
}

${ }^{1}$ M.B.B.S, Resident in Saudi Board of Family Medicine, Joint Program of Saudi Board of Family Medicine, Northern Borders Region, Arar City, Saudi Arabia

${ }^{2}$ MD., Professor of Public Health and Community Medicine, Faculty of Medicine, Mansoura University, Mansoura, Egypt

${ }^{3}$ MD., Lecturer of Public Health and Community Medicine, Faculty of Medicine, Zagazig University, Zagazig, Egypt

Type of article: Brief report

\begin{abstract}
Background: Acne vulgaris is a common heath problem affecting adolescents with considerable impact on their quality of life.

Objective: To determine the prevalence of Acne vulgaris and its psychological impact among female secondary school students.

Methods: A cross-sectional study was conducted during the period from January to March 2018, among all female secondary school students in 3 randomly selected schools, in Arar city (Saudi Arabia). The participants were clinically examined by a dermatologist to identify acne cases. Dermatological quality of life of acne cases were assessed using an Arabic version of Dermatology Life Quality Index (DLQI). Data collected were analyzed by IBM-SPSS version 20, using Chi-square, Fisher's Exact test, Mann-Whitney U, and Kruskal Wallis test. Pvalue $\leq 0.05$ was considered statically significant.

Results: The overall prevalence of Acne vulgaris was $14.3 \%$. It was not significantly affected by age, marital status or nationality of participants. Post inflammatory hyper-pigmentation and scarring were detected in $11.6 \%$ and $8.7 \%$ respectively. Twenty nine percent of the cases had no impact; $56.3 \%$ had small to moderate impact and $14.5 \%$ had large effect. The psychological impact was significantly increased with increased severity, presence of acne lesions on face and other sites, presence of hyper pigmentation and scarring $(\mathrm{p}=0.001)$.

Conclusion: Acne vulgaris had large impact on quality of life in $14.5 \%$ of cases. Students should be counseled and educated on how to deal with this dermatological problem.
\end{abstract}

Keywords: Acne vulgaris, Prevalence, Epidemiology, Quality of life, Adolescents

\section{Introduction}

Acne vulgaris is a common skin disease affecting approximately $9.4 \%$ of the world's population with the highest prevalence in adolescents. It affects over $90 \%$ of males and $80 \%$ of females in all ethnic groups $(1,2)$. The prevalence of acne in adolescents and adults varies among countries and ethnic groups (3). In the US, Bhate and Williams reported prevalence of acne in $85 \%$ of teenagers (4). In Turkey, the overall prevalence among adolescents aged between $13-19$ years was $60.7 \%$ (5). A study conducted on acne among medical students in Malaysia, reported prevalence of acne was $68.1 \% \%(6)$. Another community-based study conducted among Chinese adolescents and adults reported a 33.7\% prevalence of acne among females aged 15-19 years (7). In South-west Nigeria, Okoro et al. reported that $71.7 \%$ of secondary school female students aged 15-19 years had acne (8). In Egypt, El-hamd et al. reported prevalence of acne in $60 \%$ of female secondary school students (9). Most of the previous studies reviewed,

\section{Corresponding author:}

Dr. Manal Saeed Alanazi. Tel: +966.530426976, E-mail: M-N-L-333@hotmail.com

Received: June 05, 2018, Accepted: July 02, 2018, Published: August 2018

iThenticate screening: June 25, 2018, English editing: July 11, 2018, Quality control: July 12, 2018

This article has been reviewed / commented by three experts

Ethics approval: 39/6 (Northern Borders General Health Affairs)

(C) 2018 The Authors. This is an open access article under the terms of the Creative Commons Attribution-NonCommercialNoDerivs License, which permits use and distribution in any medium, provided the original work is properly cited, the use is non-commercial and no modifications or adaptations are made. 
reported high prevalence of acne among adolescent females (1-9). In Saudi Arabia, on reviewing the previously published studies on prevalence of acne among female adolescents, we observed variation in prevalence between different studies but the prevalence was generally high. For example, in a study done in central Saudi Arabia, AlRobaee reported a 56.2\% prevalence of acne among Qassim University students with insignificant difference between males and females (10). In Riyadh city (the capital of Saudi Arabia), the overall prevalence of Acne vulgaris among adolescent and young females was $68.2 \%$ (11). In Jizan, the overall prevalence of self-reported acne among intermediate and secondary school students was $65.1 \%$ with females more affected than males $(71 \%$ and $60 \%$. respectively) (12). In Makkah, the prevalence of Acne vulgaris among female patients (14-38 years) attending dermatology outpatient clinics of 3 hospitals was $56.6 \%$ (13). Despite this, acne is neither life threatening nor physically debilitating, but it can affect social and psychological functioning of affected patients and lead to deterioration of their quality of life (QOL). Moderate to severe acne lesions may leave post inflammatory hyper pigmentation and/or atrophic scars that can affect the quality of life and lead to reduced self-esteem, and less social interaction with others (14). Also, it can lead to anxiety, depression, and other emotional trauma that threaten the quality of life (15). Since no previous community-based studies have been conducted in the Northern Borders Region of Saudi Arabia on Acne vulgaris among adolescents, this study aimed to determine the prevalence of Acne vulgaris among female secondary school students in Arar city (the main city in the Northern Borders Region of Saudi Arabia), and to assess their dermatological quality of life index.

\section{Material and Methods}

\subsection{Research design and participants}

A cross sectional study was conducted during the period from January to March 2018 during second semester of the academic year 2017-2018. Three female secondary schools were randomly selected out of 13 schools in Arar city. All female students aged 14-21 years in selected schools were included in our study. A total of 718 participants were clinically examined by a dermatologist in a private room assigned in each school to identify acne cases.

\subsection{Instrument and data collection}

Participants with acne were interviewed by the main researcher using Dermatology Life Quality Index (DLQI) to assess the impact of acne on quality of life. DLQI Arabic version is validated by a panel of experts and examined for reliability after a pilot study (Cronbach's alpha coefficient was 0.8 . It consisted of 10 questions about disease symptoms, feelings, daily activities, type of clothing, social or physical activities, exercise, job or education, interpersonal relationships, marriage relationships, and treatment. The participants with acne were asked about problems faced during the previous week due to the acne; a duration considered to be easily and accurately recallable. Each question is scored as "very much" (score 3), "a lot" (score 2), "a little" (score 1), and "not at all" (score 0). Final DLQI score is the sum of all scores (range 0-30). High scores indicate poor QOL. According to the score obtained through this instrument, the effect of disease on QOL was divided into 5 classes: $(0-1)$ without effect, (2-5) low effect, (6-10) moderate effect, (11-20) high effect, and (21-30) severe effect (16).

\subsection{Ethical consideration}

Ethics approval was obtained from the research ethical committee of Northern Borders General Health Affairs (Ref. no.: 39/6) and the research was approved by the General Directorate of Education, Ministry of education regional office. Before the interview, participants were oriented on the study, and verbal informed consent was obtained from the participants. They were assured that collected data would be treated with high confidentiality and personal identifying information would not be published. Health education by face-to-face method and medical treatment were provided to them for free.

\subsection{Statistical Analysis}

Data were analyzed by IBM $\odot$ SPSS $\odot$ Statistics version 20 (IBM $\odot$ Corp., Armonk, NY, USA), using Chi-square, Fisher's Exact test, Mann-Whitney U, and Kruskal Wallis test. $\mathrm{P} \leq 0.05$ was considered significant.

\section{Results}

Table 1 shows the prevalence of Acne vulgaris among female secondary school students in relation to their demographic data. The overall provenance of acne was $14.3 \%$. The prevalence of acne did not significantly differ with age, marital status or nationality ( $p>0.05$ ). Regarding severity of acne, $64 \%$ had mild acne, $30.1 \%$ moderate and only $5.9 \%$ had severe acne. The majority of acne cases $(83.5 \%)$ were facial only. Post inflammatory hyperpigmentation and scarring were present in $11.6 \%$ and $8.7 \%$ respectively, and scar was absent in most of cases (91.3\%). According to the study, no psychological effect was detected in $29.1 \%$ of acne cases. Psychological impact 
was small to moderate in $56.3 \%$ and large in $14.5 \%$ of acne cases. According to Fisher's exact test, psychological impact was significantly increasing with increase of clinical severity $(p<0.001)$, presence of post inflammatory hyper-pigmentation $(p<0.001)$, scarring $(p<0.001)$, and presence of acne lesion over face and other sites $(p=0.002)$. The median score of DLQI increased significantly with increased clinical severity of acne ( $\mathrm{p}=0.001$, Kruskal-Wallis test). Regarding the site, cases with lesions over face and other sites had a significantly higher median score of DLQI than those with lesions only on the face $(\mathrm{p}=0.001$, Kruskal-Wallis test). DLQI score was higher among cases with post inflammatory hyper pigmentation and scarring ( $\mathrm{p}=0.001$, Kruskal-Wallis test). According to our findings, $55.3 \%$ of the acne cases reported complaint of physical symptoms. Embarrassment was reported by $66 \%$. Almost one-fifth $(20.4 \%)$ reported negative effect of acne on their study. Interpersonal problems were reported by $12.6 \%$ of the acne cases. All married acne cases complained of sexual difficulties. Nearly one-third (33\%) reported that treatment was taking a time or making life messy.

Table 1. Frequency distribution of Acne vulgaris in study participants, in relation to their demographic data.

\begin{tabular}{|c|c|c|c|c|}
\hline \multicolumn{2}{|c|}{ Demographic data } & Total; n (\%) & Acne cases; $\mathrm{n}(\%)$ & p-value \\
\hline \multirow[t]{3}{*}{ Age (year) } & $\leq 16$ & $270(37.6)$ & $40(14.8)$ & \multirow[t]{3}{*}{0.357} \\
\hline & 17 & $226(31.5)$ & $37(16.3)$ & \\
\hline & $18+$ & $222(30.9)$ & $26(11.7)$ & \\
\hline \multirow[t]{2}{*}{ Marital status } & Married & $9(1.3)$ & $3(33.3)$ & \multirow[t]{2}{*}{0.10} \\
\hline & Single & 709 (98.7) & $100(14.1)$ & \\
\hline \multirow[t]{2}{*}{ Nationality } & Saudi & $694(96.7)$ & $100(14.4)$ & \multirow[t]{2}{*}{0.79} \\
\hline & Non Saudi & $24(3.3)$ & $3(12.5)$ & \\
\hline \multicolumn{2}{|l|}{ Total } & $718(100.0)$ & $103(14.3)$ & \\
\hline
\end{tabular}

\section{Discussion}

This study was conducted to determine the prevalence of Acne vulgaris and its psychological impact on female secondary school students aged 14-21 years. The overall prevalence of acne among female secondary school students was $14.3 \%$ which is much lower than reported in previous studies in other countries: Australia, UK, Turkey, Malaysia, China, South west Nigeria and Egypt (4-10). Also, it is much lower than that reported by other studies conducted in Saudi Arabia, including Qassim, Riyadh, Jizan and Makkah (11-14). This might be attributed to the multifactorial nature of the disease and duration of the study. The percentage of acne cases was measured in three months only (second semester). Also, this study was conducted during winter season and it is known that during winter, the skin surface lipid production diminishes (17) and there is negative correlation between the incidence of acne and skin surface lipid $(18,19)$. Other factors that might explain the differences in prevalence of acne between different studies include differences in: study design, age range, pubertal age (commencement of menstruation), genetic difference, lifestyle, type of skin, use of cosmetics, environmental factors and mode of diagnosis of acne either through self-reporting, diagnosis by general clinician or by dermatologist. In the present study, the prevalence of acne among female secondary school students was not significantly affected by age. This might be attributed to the narrow age range. Contrary to our study, Abo El-Fetoh et al. found that the mean age of acne cases $( \pm \mathrm{SD})$ was $21.21( \pm 4.6)$ and the mean age of onset of acne $( \pm$ SD) was $15.5( \pm 2.9)$. they stated that acne usually starts in adolescence, peaks at the ages of 14 to 19 years and frequently resolves by mid-twenties (11).

Regarding severity of acne cases, this study found that $64 \%$ had mild acne, $30.1 \%$ moderate and only $5.9 \%$ had severe acne. This finding is in agreement with an Indian study (20) that found that Grade I acne was the most common as it affected $60.2 \%$ of participants and a Chinese study (7) that found $68.4 \%$ of patients with acne were mild. A study in Riyadh also reported that more than half (57.5\%) of cases had first-degree acne (11). An Egyptian study reported mild acne in 53\% of the cases (9). Comparable figures were reported by Okoro et al. in 2016, who found that $88.6 \%$ of the participants were classified as having mild acne and $11.4 \%$ as having moderate acne (8). Mild degree is the commonest clinical presentation. Regarding the site of acne, the face was affected by acne in all patients of our study. This finding is consistent with the finding of the Brazilian study (3) which reported that the face was affected in $97.5 \%$ of acne patients, and the Riyadh study (11) that found that the face was affected in $96.4 \%$ of cases. Also, Abo El-Fetoh et al. found that the acne site was the face in $46.2 \%$, the back in $3.6 \%$ and multiple sites in $50.2 \%$ of the cases (21). The face is often involved in Acne vulgaris, and as facial appearance represents an important aspect of one's perception of body image, patients usually suffer from psychosocial distress as a result of the disease process. 
In the current study, post inflammatory hyper pigmentation and scarring were detected in $11.6 \%$ and $8.7 \%$ respectively. These findings are far less than those reported by Hazarika and Archana, who found that $79 \%$ of acne patients had post inflammatory hyper pigmentation and $75 \%$ had post acne scarring, but this difference might be explained by the fact that our study is a community based study and the latter study is a hospital based study (20). This study revealed a negative impact of acne on the quality of life of female secondary school students. Acne had affected quality of life of $71.0 \%$ of subjects. This is in agreement with the study of Hazarika and Archana (20), which reported that $66 \%$ of acne cases had impairment in their quality of life (moderate impairment in QOL in $37 \%$ and very large impairment in $29 \%$ of cases). A study done by Al-Robaee, 2005, revealed that acne had no or minimal effect on self-image in $46 \%$ of patients, and in most of the patients $(73 \%)$, it had no minimal effect on their relationships (10). Another study among teenage Scottish schoolchildren reported that $50 \%$ of pupils were emotionally affected by their acne (22). However, Shen et al., in their Chinese study found that $30.8 \%$ of acne cases had a negative impact on their quality of life (7).

The degree of impairment in QOL significantly increased with increase of clinical severity of acne, with presence of post acne hyper pigmentation and scarring. The same has been reported by Tasoula et al., who reported a negative correlation between acne severity and better quality of life (23). However, other studies reported no significant association between severity of acne and QOL $(12,24)$. In our study, the mean score of DLQI was 5.26. This finding coincides with what has been reported in the Iranian study which has revealed that acne affected quality of life of $51.8 \%$ with mean score of DLQI was 6.42 (25). On the other hand, in a study by Abdel-hafez in Egypt, the mean DLQI score was 11.9 and 15.0 in female and male subjects, respectively, which are worse compared to the results of our study (26). In a study by Walker (22), performed on students in Scotland, the mean scores of DLQI and CADI were, respectively, 1.7 and 1.9 and the quality of life of patients was better, when compared to the present study. In this study, as regards the psychological impact of Acne vulgaris, our study found that $29.1 \%$ of the cases had no impact, $56.3 \%$ had small to moderate impact and $14.5 \%$ had large effect. In Riyadh, another study found that most cases $(82.6 \%)$ reported a feeling of depression due to the appearance of acne, more than half $(57.8 \%)$ of the cases reported impact of acne on social relations and $54.2 \%$ had an impact on self-confidence (10). The most common psychological domain that affected the female secondary school students with acne was embarrassment/selfconsciousness. Almost two-thirds of subjects reported embarrassment/self-consciousness due to acne, which was congruent to previous studies $(23,25)$. The qualitative study of Magin et al., on the psychological sequelae of acne, reported that, at least to some degree, acne negatively affected self-image in all patients. Embarrassment and selfconsciousness were directly linked to low self-image/self-esteem and this ultimately led to a decrease in selfconfidence (27). Other Studies have also shown that acne has serious effects on body image, self-esteem, and socialization and even may lead to feelings of anger, anxiety, depression, and social dysfunction (28-30).

Physical symptoms were reported by $55 \%$ of patients in the present study. This finding is in agreement with the Reich et al. study in 2008, which reported $50 \%$ of acne cases to having experienced itchiness (30). While, Tasoula et al., reported $25 \%$ of cases of facial acne and $33 \%$ cases of acne in the back to be having itchiness as a physical symptom (23). In another study, $88 \%$ of acne patients had physical symptoms (20). In this study, problems in daily activities (shopping, looking after home, garden), were complained about by $39 \%$ of students with acne which is much lower than that which was reported by Hazarika and Archana, 2016, who found that $69 \%$ of acne patients had difficulty in daily activities. Thus, problems in daily activities may be attributed to avoidance behavior, anger, and frustration (20). One's image is often appraised through style of clothing and thus clothes form an important component of social acceptance. In our study, $29 \%$ of students reported the difficulty in obtaining suitable clothing to be attributable to acne. This finding is consistent with what has been reported in a study in Greece (23), which showed that modifications to dressing style was observed in $21.3 \%$ of acne adolescents. In this study, $31 \%$ of acne students reported acne affected their social activities. This finding is much lower than that reported by Hazarika and Archana, who found that $68 \%$ of acne patients felt a negative influence of acne on their social/leisure activities (20). In the Greece study, $19.2 \%$ of students were affected in their social life (23). Another study among teenage Scottish schoolchildren reported that twenty percent of pupils were affected in their personal and social lives because of their acne (22). In the present study, $23 \%$ of acne students reported that they had difficulty in sports because of acne; while, a study among Scottish students found that $10 \%$ of acne sufferers avoided swimming and other sports because of embarrassment (22). Another study in Greece, reported $14.4 \%$ of acne patients having difficulty in sports attributed to acne (23).

In the present study, $20 \%$ of acne students experienced a negative effect of acne on their studies. An Indian study showed that $57 \%$ of patients reported negative effect of acne on work/study (20). Twenty-one percent of pupils felt 
that acne affected their schoolwork and personal activities (26). Similar findings were also reported by Walker and Lewis-Jones (22). In the present study, only $13 \%$ of acne students reported problems with peers, friends and relatives. A similar finding was in the Greece study, which found $19.2 \%$ of acne patients were affected in their personal lives especially in their relationship building (23). However, the study of Hazarika and Archana showed that a much higher percentage (75\%) of acne subjects suffered interpersonal problems (20). A total of $25 \%$ of pupils under treatment for acne reported that the treatment was an unpleasant experience (26). In the present study, 35\% reported that applying treatment and home remedies of acne were time consuming or the cause of interruptions to daily life. However, Hazarika and Archana found that $45 \%$ of acne subjects suffered from unpleasant treatment (20). The observed differences in different psychological domains that reflect the impact of acne on QOL may be due to the difference in disease severity, cultural differences, and also differences in individual perceptions, study design and assessment tool. Regarding the study limitations, the study did not include assessment of risk factors such as dietary history, menstrual history, family history and use of topical steroids that could alter the pattern and severity of acne lesions.

\section{Conclusions}

The prevalence of Acne vulgaris among female secondary school students in Arar city, KSA, during the second semester of the academic year 2017-2018 was 14.3\%. It had a considerable impact on their quality of life. Proper dermatological care should be offered in secondary schools. Counseling of adolescents is a necessity to improve their quality of life. Further studies are recommended to investigate the underlying risk factors and prevalence of acne in Arar city.

\section{Acknowledgments:}

The authors would like to thank the participants for their cooperation, and Dr. Hanan Abdel Monem (Dermatologist at Arar Central Hospital) for her great effort and help in clinical examination of the participants.

\section{Conflict of Interest:}

There is no conflict of interest to be declared.

Authors' contributions:

All authors contributed to this project and article equally. All authors read and approved the final manuscript.

\section{References:}

1) Yosipovitch G, Tang M, Dawn AG, Chen M, Goh CL, Huak Y, et al. Study of psychological stress, sebum production and acne vulgaris in adolescents. Acta Derm Venereol. 2007: 87(2): 135-9. doi: 10.2340/00015555-0231. PMID: 17340019.

2) Tan J, Bhate KA. Global perspective on the epidemiology of acne. Br J Dermatol. 2015: 172(1): 3-12. doi: 10.1111/bjd.13462. PMID: 25597339.

3) Bagatin E, Timpano DL, Guadanhim LR, Nogueira VM, Terzian LR, Steiner D, et al. Acne vulgaris: prevalence and clinical forms in adolescents from São Paulo, Brazil. An Bras Dermatol. 2014; 89(3): 42835. doi: 10.1590/abd1806-4841.20142100. PMID: 24937816, PMCID: PMC4056700.

4) Bhate K, Williams HC. Epidemiology of acne vulgaris. Br J Dermatol. 2013; 168: 474-85. doi: 10.1111/bjd.12149. PMID: 23210645.

5) Aksu AE, Metintas S, Saracoglu ZN, Gurel G, Sabuncu I, Arikan I, et al. Acne: prevalence and relationship with dietary habits in Eskisehir, Turkey. J Eur Acad Dermatol Venereol. 2012; 26(12): 1503-9. PMID: 22070422.

6) Muthupalaniappen L, Tan HC, Puah JW, Apipi M, Sohaimi AE, Mahat NF, et al. Acne prevalence, severity and risk factors among medical students in Malaysia. Clin Ter. 2014; 165(4): 187-92. PMID: 25203331.

7) Shen Y, Wang T, Zhou C, Wang X, Ding X, Tian S, et al. Prevalence of Acne Vulgaris in Chinese Adolescents and Adults: A Community-based Study of 17,345 Subjects in Six Cities. Acta Derm Venereol. 2012; 92: 40-4. doi: 10.2340/00015555-1164. PMID: 21710106.

8) Okoro E, Ogunbiyi A, George A. Prevalence and pattern of acne vulgaris among adolescents in Ibadan, south-west Nigeria. Journal of the Egyptian Women's Dermatologic Society. 2016; 13: 7-12. doi: 10.1097/01.EWX.0000470561.85599.0d.

9) El-Hamd MA, Nada EEA, Moustafa MA, Mahboob-Allah RA. Prevalence of acne vulgaris and its impact of the quality of life among secondary school-aged adolescents in Sohag Province, Upper Egypt. J Cosmet Dermatol. 2017; 16(3): 370-3. doi: 10.1111/jocd.12328. 
10) Al Robaee AA. Prevalence, knowledge, beliefs and psychosocial impact of acne in University students in Central Saudi Arabia. Saudi Med J. 2005; 26(12): 1958-61. PMID: 16380781.

11) Abo El-Fetoh NM, Alghamdi RS, Albarqi WA, Asiri SAM, Alruwaili NQ. Epidemiology Of Acne Vulgaris In Adolescent And Young Females In Riyadh City, Kingdom Of Saudi Arabia. Int J Adv Res. 2016; 4(12): 589-98. doi: 10.21474/IJAR01/2434.

12) Bajawi S, Salih S, Mahfouz MS, Bajawi N, Asiri B. Acne Vulgaris Awareness and Impact on Quality of Life and Psychological Status of Adolescent School Children in Jazan, Saudi Arabia. International Journal of Sciences: Basic and Applied Research. 2016; 25(2): 374-84.

13) Bahattab ES, Alharbi AA, Alsulami BA, Alfahmi KZ, Alzahrani SF, Sharkar OA, et al. Acne Vulgaris and Its Influence on Quality of Life of Female Patients, Makkah, Saudi Arabia. Int J Med Res Prof. 2017; 3(1); 184-8.

14) Alajlan A, Alhazzani Y, Alhowaish N. Prevalence, level of knowledge and lifestyle association with acne vulgaris among medical students. Journal of Dermatology \& Dermatologic Surgery. 2017: 21(2): 58-6. doi: 10.1016/j.jdds.2017.01.001.

15) Al Natour S. Acne vulgaris: Perceptions and beliefs of Saudi adolescent males. J Fam Community Med. 2017: 24(1): 34. doi: 10.4103/2230-8229.197180. PMID: 28163574, PMCID: PMC5248432.

16) Cardiff Faculty of Medicine, Dermatology Department. Dermatology Quality of Life Index Arabic version, 2017. Available from: http://sites.cardiff.ac.uk/dermatology.

17) Meyer K, Pappas A, Dunn K, Cula GO, Seo I, Ruvolo E, et al. Evaluation of seasonal changes in facial skin with and without acne. J Drugs Dermatol. 2015; 14: 593-601. PMID: 26091385.

18) Ikaraoha CI, Taylor GO, Anetor JI, Onuegbu JA. Pattern of skin surface lipids in some south-western nigerians with acne vulgaris. West Afr J Med. 2004; 23: 65-8. doi: 10.4314/wajm.v23i1.28086. PMID: 15171531.

19) Shengjie L, Zhang Y, Zheng G, et al. Investigation and analysis of sick status and influencing factors on the undergraduates facial acne vulgaris in Taian. Chin J Dermato-venereol. 2012; 26: 625-7.

20) Hazarika N, Archana M. The psychosocial impact of acne vulgaris. Indian Journal of Dermatology. 2016; 61(5): 515-20. doi: 10.4103/0019-5154.190102. PMID: 27688440, PMCID: PMC5029236.

21) Abo El-Fetoh NM, Alenezi NG, Alshamari NG, Alenezi OG. Epidemiology of acne vulgaris in adolescent male students in Arar, Kingdom of Saudi Arabia. J Egypt Public Health Assoc. 2016; 91(3): 144-9. doi: 10.1097/01.EPX.0000492401.39250.62. PMID: 27749646.

22) Walker N, Lewis-Jones MS. Quality of life and acne in Scottish adolescent schoolchildren: use of the Children's Dermatology Life Quality Index (CDLQI) and the Cardiff Acne Disability Index $\gamma$ opy; (CADI). J Eur Acad Dermatol Venereol. 2006; 20(1): 45-50. doi: 10.1111/j.1468-3083.2005.01344.x. PMID: 16405607.

23) Tasoula E, Gregoriou S, Chalikias J, Lazarou D, Danopoulou I, Katsambas A, et al. The impact of acne vulgaris on quality of life and psychic health in young adolescents in Greece. Results of a population survey An Bras Dermatol. 2012; 87(6): 862-9.

24) Kokandi A. Evaluation of Acne Quality of Life and Clinical Severity in Acne Female Adults. Dermatol Res Pract. 2010; 2010. pii: 410809. doi: 10.1155/2010/410809. PMID: 20706683, PMCID: PMC2913789.

25) Safizadeh H, Shamsi-Meymandy S, Naeimi A. Quality of Life in Iranian Patients with Acne. Dermatology Research and Practice. 2012. doi: 10.1155/2012/571516.

26) Abdel-Hafez K, Mahran AM, Hofny ERM, Mohammed KA, Darweesh AM, Aal AA, The impact of acne vulgaris on the quality of life and psychologic status in patients from upper Egypt. International Journal of Dermatology. 2009; 48(3): 280-5. doi: 10.1111/j.1365-4632.2009.03838.x. PMID: 19261017.

27) Magin P, Adams J, Heading G, Pond D, Smith W. Psychological sequelae of acne vulgaris: results of a qualitative study. Can Fam Physician. 2006; 52: 978-9. PMID: 17273501, PMCID: PMC1781509.

28) Thomas DR. Psychosocial effects of acne. J Cutan Med Surg. 2004; 8 Suppl 4: 3-5. doi: 10.1007/s10227004-0752-x. PMID: 15778823.

29) Niemeier V, Kupfer J, Gieler U. Acne vulgaris-psychosomatic aspects. J Dtsch Dermatol Ges. 2006; 4(12): 1027-36. doi: 10.1111/j.1610-0387.2006.06110.x. PMID: 17176410.

30) Reich A, Trybucka K, Tracinska A, Samotij D, Jasiuk B, Srama M, et al. Acne itch: Do acne patients suffer from itching? Acta Derm Venereol. 2008; 88: 38-42. doi: 10.2340/00015555-0355. PMID: 18176749. 